\title{
DYNAMICS OF THE NON-CONTACT ROUNDNESS MEASUREMENT WITH AIR GAGES
}

\author{
Czesław Janusz JERMAK*, Mirosław RUCKI ${ }^{*}$ \\ *Poznan University of Technology, Institute of Mechanical Technology, Division of Metrology and Measurement Systems, \\ ul. Piotrowo 3, 60-965 Poznań, Poland \\ czeslaw.jermak@put.poznan.pl, miroslaw.rucki@gmail.com
}

received 11 December 2015, revised 20 July 2016, accepted 22 July 2016

\begin{abstract}
The paper presents the results of investigations on the air gages dynamic characteristics in the measurement of the round profiles of motor cylinders. The principle of the measuring device is explained, and the analysis of the air gages dynamics is described. The results of dynamic calibration enabled to eliminate those configurations of air gages that may not meet the requirements of the measurement they were designed for. After the proper air gages were chosen, the entire system underwent the accuracy test and passed it successfully revealing the method accuracy better than $10 \%$ compared to the reference measurement.
\end{abstract}

Key words: Air Gage, Back-Pressure, Out-of-Roundness

\section{INTRODUCTION}

The quality management in 25 years has shifted researches away from TQM to focus on the tools and techniques and improving measurement systems (O'Neil, 2016). Especially valuable in that context are non-contact measuring techniques (Valicek et al., 2007), among others air gages (Shiraishi, 2002). Despite the air gages are unable to perform a measurement with nanoscale accuracy, they still find their application in the industrial precise measuring tasks like in-process inspection (Vacharanukul and Mekid, 2005) both passive and active type (Wang et al., 2005; Menzies and Koshy 2009) or automatic control (Wieczorkowski, 1995).

Even though the investigations on the dynamic properties of the air gages had been performed since the middle of the $20^{\text {th }}$ century both in Western countries and in the Soviet Union (Yribarren, 1955; Dmitriev and Chernyshev, 1958), the long response time of the devices seemed to be the main obstacle for their development (Tsidulko, 1965). Nowadays, however, application of the piezoresistive pressure transducers and reduction of the measuring chamber volume (Jermak and Rucki, 2012) allowed to apply the air gage in the fast non-contact measurement of complicated geometrical features like roundness and cylindricity. The goal of the present study was to analyze dynamic properties of the air gauges and to choose the ones with proper dynamic characteristics to be implemented in the Geoform device dedicated for the roundness assessment. The device with chosen air gauges underwent overall accuracy test through a comparative analysis with the reference measurement data.

\section{OUT-OF-ROUNDNESS MEASUREMENT WITH THE AIR GAGES}

The team of the Division of Metrology and Measurement Systems (Poznan University of Technology) has proposed the innovative device Geoform designed for the complex measurement of the cylinders for the motor industry. The series of investigations proved the capability of the air gages to measure within assumed tolerances (Derezynski and Jakubowicz, 2016). In order to achieve non-contact measurement with high dynamics, the small chamber air gages (back-pressure type) had been proposed.

A simple one-cascade back-pressure gage consists of two nozzles (inlet $d_{w}$ and measuring one $d_{p}$ ), as it is shown in the Fig. 1. The pressured air of pressure $p_{z}$ enters the measuring chamber of certain volume $V_{k}$ through the inlet nozzle, and leaves through the measuring one. Here, the surface of the measured detail serves as a flapper which restricts the air outflow, so the pressure $p_{k}$ in the chamber in some extend is proportional to the displacement $s$. The volume $V_{k}$ of the chamber depends on its length $l_{k}$ and inner diameter $d_{k}$.

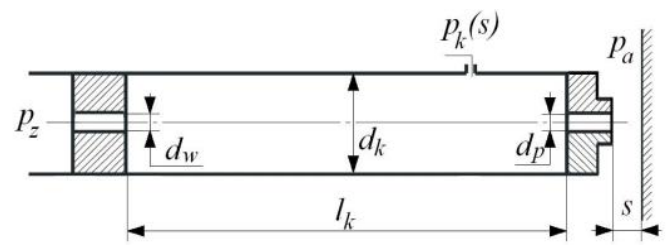

Fig. 1. Scheme of the back-pressure air gage

Typically, engineers do not calculate the exact response time or amplitude characteristics of the air gages. For instance, Jun Liu et al. (2012) consider the velocity of the gage head during the form measurement relatively low so that the dynamic error can be ignored, or Grandy et al. (2009) use the simplified dynamic models with reference to the geometric parameters of an air gage. It was proved that the dynamics of the air gages with small volumes (ca. 0.5 to $4.0 \mathrm{~cm}^{3}$ ) combined with a piezoresistive pressure transducer could be modelled as a first-order dynamic system, but some additional knowledge is required in order to avoid unexpected dynamic errors (Rucki and Jermak, 2012). Hence, after exact analysis of their dynamic characteristics, the devices could be applied for the measurement in dynamic conditions, like 
a cylindricity measurement.

Traditionally, quality control is performed offline, after a part is produced (Gao et al., 2014), and the Geoform device was designed for this kind of measurement. It is based on the complete automatic set, where the detail is placed manually (Fig. 2, left). The measuring head goes up from lower part of the set, and perform the measurement in three intersections (bottom, middle and top) turning around $360^{\circ}$ (Fig. 2, right). The novelty of the method consists of following: the measuring head contains three independent air gages (Fig. 3), it is placed on the flexible rod (a floating head), and it is based on the original algorithm designed for analysis of three independent signals to determine the roundness of the measured detail.


Fig. 2. The Geoform equipment (left) and the scheme of measurement (right) (Jermak et al., 2010)

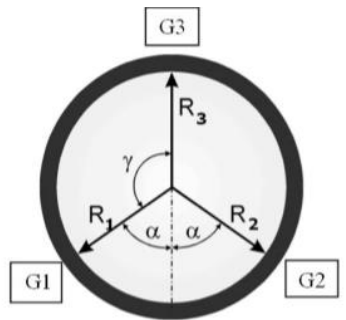

Fig. 3. Position of three air gages in the Geoform measuring head

The algorithm consists of the following operations:

- data collection which is performed from three air gages independently, when the gage head turns $370^{\circ}$ (there are up to 1000 points recorded),

- smoothening of the obtained data in order to eliminate the excessive errors,

- profile closure which is necessary because of flexible type of the gage head (the coordinates of the points corresponding with $0^{\circ}$ and $360^{\circ}$ are different and need to be adjusted to each other),

- interpolation according to the Bessel's formula (Pollard, 1977) performed in order to reduce the number of analyzed points down to 720 ,

- calculation of the profile and its out-of-roundness.

The calculations are performed as if the typical V-block measurement is done (Stepien, 2010), only instead of fixed two points of the V-block, the collected data from two air gages (G2 and G1 shown in the Fig. 3) are used. To obtain the would-be value $\Delta W$ of V-block measurement from the collected points $\mathrm{G} 1, \mathrm{G} 2$ and $\mathrm{G} 3$, the following formula is applied (Cellary and Jermak, 2009):

$\Delta W=\Delta R_{3}+\frac{\Delta R_{1}+\Delta R_{2}}{2 \cos \alpha}$,

where: $\Delta R_{1}, \Delta R_{2}$ and $\Delta R_{3}$ - indication changes for the gages $G 1$, $\mathrm{G} 2$ and $\mathrm{G} 3$ respectively, $2 \alpha$ - the angle between gages $\mathrm{G} 1$ and $\mathrm{G} 2$.

The measuring task was defined by the initial laboratory measurement of the cylinders for motor industry with the reference device Talyrond 365. The assumed tolerance was $15 \mu \mathrm{m}$ near the upper and lower edges, and $10 \mu \mathrm{m}$ in the middle part of the cylinder. The highest amplitudes revealed $2^{\text {nd }}$ and $3^{\text {rd }}$ harmonics: $2.6 \mu \mathrm{m}$ and $0.98 \mu \mathrm{m}$ respectively. Amplitudes of $4^{\text {th }}, 5^{\text {th }}$ and $7^{\text {th }}$ harmonics were of similar distribution type and did not exceed $0.56 \mu \mathrm{m}$ (mean values lower than $0.08 \mu \mathrm{m}$ ).

In order to enable the reliable harmonic analysis up to $15^{\text {th }}$ harmonics, and to reduce the measurement time down to $10 \mathrm{~s}$, it was needed to evaluate the dynamic characteristics of the applied air gages, and to shape them to ensure the acceptable error level.

\section{SINE INPUT ANALYSIS}

Dynamic variables are time or space dependent in both their magnitude and frequency content. A dynamic calibration determines the relationship between an input of known dynamic behaviour and the measurement system output. Usually, such calibrations involve applying either a sinusoidal signal or a step change as the known input signal (Figliola and Beasley, 2006). When the input signal forms a simple periodic function, $F(t)=A \cdot \sin \omega t$, and the initial conditions are $y(0)=y_{0}$, then the function could be written as following:

$T \dot{y}+y=K A \sin \omega t$,

where: $T$ - time constant, $K$ - static sensitivity (multiplication), $A$ - amplitude, $\omega=2 \pi f$ - rotational speed, $f$ - frequency.

The amplitude of the steady response depends on the value of the applied frequency $f$.

In order to generate a sine input signal, the dedicated laboratory equipment has been developed (Fig. 4). It consists of replaceable model of the air gage (1) with the pressure transducer (3), eccentric shaft of highly smooth surface and eccentricity $e=20 \mu \mathrm{m}$ (2) which rotary speed can be changed from $\omega=0.1$ $\mathrm{rad} / \mathrm{s}$ up to $20 \mathrm{rad} / \mathrm{s}$, and the electronic devices for conditioning and acquisition of the measurement signals (4). Fig. 5 presents the block diagram of the sine input analysis system.

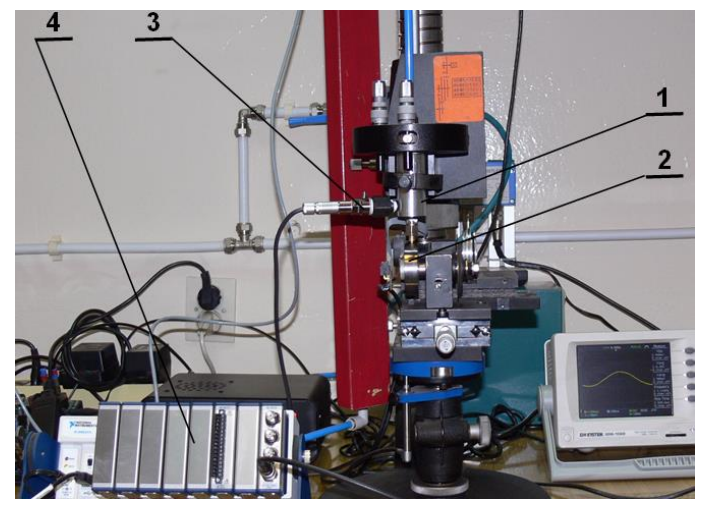

Fig. 4. Laboratory equipment for the sine input analysis of the air gages 


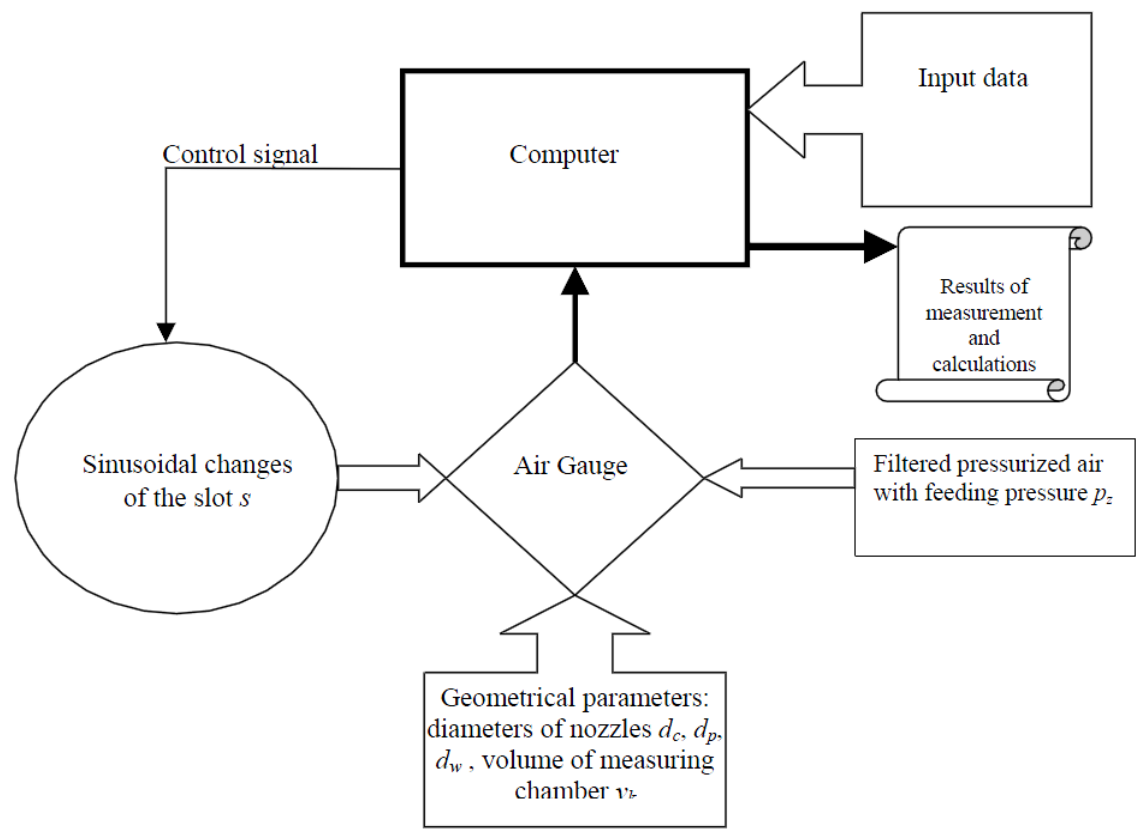

Fig. 5. Block diagram of the dynamic calibration setup (Rucki and Barisic, 2009)

The system presented in the Figs. 4 and 5 enables to analyse the air gages of various geometrical parameters (nozzles diameters and dimensions of the measuring chambers explained in the Fig. 1). The data of the examined air gauge is input into the computer, as well as the conditions of experiment. The computer controls the measurement process generating the sinusoidal changes of slot $s$ and processes the collected measurement data.

The measurement system collected 20 periods of the alternating pressure for each assumed rotational speed with sampling time 0.001 of the examined period. Then, the corrected (true) value of the sine input was calculated, as well as the amplitude of the air gage response. The calculation algorithm was based on the spline functions of the $2^{\text {nd }}$ order and the least square method. The obtained results are the amplitude-frequency characteristics as well as the time constant and frequency. The value $f_{0.05}$ means a frequency when the dynamic error $\delta(\omega)$ is smaller than $5 \%$.

During the roundness measurement, the measured cylinder typically rotates with a speed of ca. $6 \mathrm{rpm}$. Therefore, to perform the registration of at least 15 harmonics of the profile with the acceptable amplitude error below $5 \%$, the upper frequency bound $f_{0.95}$ could not be lower than $1.5 \mathrm{~Hz}$. From the metrological perspective, it should be even higher to reduce the dynamic error as well as the measurement time. Hence, the following criteria were set to evaluate the dynamic quality of examined air gages:

- upper frequency bound should be $f_{0.95}>1.5 \mathrm{~Hz}$,

- time constant $T$ should not exceed $30 \mathrm{~ms}$.

Because of strong evidence that the outer diameter of the measuring nozzle $d_{c}$ have some impact on the dynamical characteristics (for larger $d_{d} / d_{p}$ ratio the time constant $T$ appeared to be longer) (Rucki, 2011), that parameter was taken into consideration. Thus, the following geometry of the air gages underwent examinations:

- the measuring nozzles of inner diameters $d_{p}=1.211,1.405$ and $1.610 \mathrm{~mm}$, of the ratios $D_{c}=d_{c} / d_{p}=1.5,2$ and 3 ,
- the volumes of the measuring chambers $V_{k 1}=0.25, V_{k 2}=1.22$ and $V_{k 3}=3.90 \mathrm{~cm}^{3}$,

- the inlet nozzles of the diameters $d_{w}=0.570,0.625,0.720$, 0.830 and $1.020 \mathrm{~mm}$.

\section{MEASUREMENT RESULTS}

From the experimental amplitude-frequency characteristics obtained with the experimental setup described above, the values of upper frequency bound $f_{0.95}$ and time constant $T$ was calculated for each examined air gage proposed to be applied in the Geoform device. The results are presented in the Tables 1 to 6 . The same results for the smallest measuring nozzle $d_{p}=1.211$ $\mathrm{mm}$ and the smallest chamber volume $V_{k 1}=0.25 \mathrm{~cm}^{3}$ are presented graphically in the Fig. 6 .
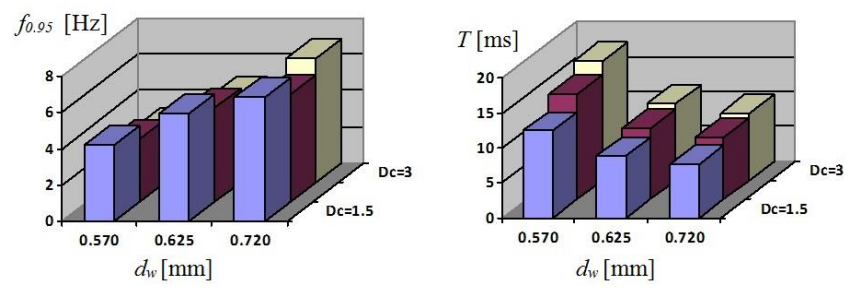

Fig. 6. Graphs of frequency $f_{0.95}$ (left) and time constant $T$ (right) for the air gage with $d_{p}=1.211 \mathrm{~mm}$ and $V_{k 1}=0.25 \mathrm{~cm}^{3}$

Using the time constant values (Tabs. 4-6), the amplitudefrequency characteristics were calculated. Fig. 7 presents the graph showing the influence of the measuring chamber volume on the obtained characteristics. 
Dynamics of the Non-Contact Roundness Measurement with Air Gages

Tab. 1. Values of the upper frequency bound $f_{0.95}[\mathrm{~Hz}]$ for the chamber $V_{k 1}=0.25 \mathrm{~cm}^{3}$

\begin{tabular}{|c|c|c|c|c|c|c|c|c|c|}
\hline$d_{p}[\mathrm{~mm}]$ & \multicolumn{3}{|c|}{1.211} & \multicolumn{3}{c|}{1.405} & \multicolumn{3}{c|}{1.610} \\
\hline $\boldsymbol{d}_{\boldsymbol{w}}[\mathrm{mm}]$ & $\mathbf{0 . 5 7 0}$ & $\mathbf{0 . 6 2 5}$ & $\mathbf{0 . 7 2 0}$ & $\mathbf{0 . 6 2 5}$ & $\mathbf{0 . 7 2 0}$ & $\mathbf{0 . 8 3 0}$ & $\mathbf{0 . 7 2 0}$ & $\mathbf{0 . 8 3 0}$ & $\mathbf{1 . 0 2 0}$ \\
\hline $\boldsymbol{d}_{\mathbf{n}} \boldsymbol{d}_{\boldsymbol{w}} / \boldsymbol{d}_{p}$ & $\mathbf{0 . 4 7 1}$ & $\mathbf{0 . 5 1 6}$ & $\mathbf{0 . 6 0 3}$ & $\mathbf{0 . 4 4 4}$ & $\mathbf{0 . 5 2 0}$ & $\mathbf{0 . 5 9 1}$ & $\mathbf{0 . 4 4 7}$ & $\mathbf{0 . 5 1 6}$ & $\mathbf{0 . 6 3 3}$ \\
\hline$D_{c}=1.5$ & 4.18 & 5.91 & 6.85 & 5.62 & 8.80 & 9.67 & 6.41 & 9.89 & 12.45 \\
\hline$D_{c}=2$ & 3.50 & 5.21 & 5.94 & 5.12 & 6.86 & 9.04 & 6.01 & 9.46 & 9.74 \\
\hline$D_{c}=3$ & 3.08 & 4.79 & 6.85 & 4.88 & 5.95 & 8.37 & 6.04 & 8.52 & 9.12 \\
\hline
\end{tabular}

Tab. 2. Values of the upper frequency bound $f_{0.95}[\mathrm{~Hz}]$ for the chamber $V_{k 2}=1.22 \mathrm{~cm}^{3}$

\begin{tabular}{|c|c|c|c|c|c|c|c|c|c|}
\hline$d_{p}[\mathrm{~mm}]$ & \multicolumn{3}{|c|}{1.211} & \multicolumn{3}{c|}{1.405} & \multicolumn{3}{c|}{1.610} \\
\hline $\boldsymbol{d}_{\boldsymbol{w}}[\mathrm{mm}]$ & $\mathbf{0 . 5 7 0}$ & $\mathbf{0 . 6 2 5}$ & $\mathbf{0 . 7 2 0}$ & $\mathbf{0 . 6 2 5}$ & $\mathbf{0 . 7 2 0}$ & $\mathbf{0 . 8 3 0}$ & $\mathbf{0 . 7 2 0}$ & $\mathbf{0 . 8 3 0}$ & 1.020 \\
\hline $\boldsymbol{d}_{\mathbf{d}} \boldsymbol{d}_{\boldsymbol{w}} / \boldsymbol{d}_{\boldsymbol{p}}$ & $\mathbf{0 . 4 7 1}$ & $\mathbf{0 . 5 1 6}$ & $\mathbf{0 . 6 0 3}$ & $\mathbf{0 . 4 4 4}$ & $\mathbf{0 . 5 2 0}$ & $\mathbf{0 . 5 9 1}$ & $\mathbf{0 . 4 4 7}$ & $\mathbf{0 . 5 1 6}$ & $\mathbf{0 . 6 3 3}$ \\
\hline$D_{c}=1.5$ & 3.82 & 4.02 & 4.52 & 4.31 & 4.84 & 5.01 & 4.17 & 7.31 & 8.32 \\
\hline$D_{c}=2$ & 3.11 & 3.38 & 3.98 & 3.89 & 3.98 & 5.12 & 5.02 & 6.80 & 7.02 \\
\hline$D_{c}=3$ & 2.62 & 2.84 & 3.01 & 3.42 & 4.02 & 5.46 & 5.77 & 6.45 & 6.85 \\
\hline
\end{tabular}

Tab. 3. Values of the upper frequency bound $f_{0.95}[\mathrm{~Hz}]$ for the chamber $V_{k 3}=3.90 \mathrm{~cm}^{3}$

\begin{tabular}{|c|c|c|c|c|c|c|c|c|c|}
\hline$d_{p}[\mathrm{~mm}]$ & \multicolumn{3}{|c|}{1.211} & \multicolumn{3}{|c|}{1.405} & \multicolumn{3}{c|}{$\mathbf{1 . 6 1 0}$} \\
\hline $\boldsymbol{d}_{\boldsymbol{w}}[\mathrm{mm}]$ & $\mathbf{0 . 5 7 0}$ & $\mathbf{0 . 6 2 5}$ & $\mathbf{0 . 7 2 0}$ & $\mathbf{0 . 6 2 5}$ & $\mathbf{0 . 7 2 0}$ & $\mathbf{0 . 8 3 0}$ & $\mathbf{0 . 7 2 0}$ & $\mathbf{0 . 8 3 0}$ & $\mathbf{1 . 0 2 0}$ \\
\hline $\boldsymbol{d}_{\mathbf{n}=\boldsymbol{d}_{\boldsymbol{w}} / \boldsymbol{d}_{p}}$ & $\mathbf{0 . 4 7 1}$ & $\mathbf{0 . 5 1 6}$ & $\mathbf{0 . 6 0 3}$ & $\mathbf{0 . 4 4 4}$ & $\mathbf{0 . 5 2 0}$ & $\mathbf{0 . 5 9 1}$ & $\mathbf{0 . 4 4 7}$ & $\mathbf{0 . 5 1 6}$ & $\mathbf{0 . 6 3 3}$ \\
\hline$D_{c}=1.5$ & 1.53 & 1.81 & 2.27 & 2.02 & 2.86 & 3.10 & 2.46 & 4.12 & 4.96 \\
\hline$D_{c}=2$ & 1.48 & 1.88 & 2.37 & 1.95 & 2.01 & 3.11 & 3.32 & 3.43 & 4.08 \\
\hline$D_{c}=3$ & 1.25 & 1.68 & 2.19 & 1.68 & 2.83 & 3.08 & 2.06 & 3.04 & 3.66 \\
\hline
\end{tabular}

Tab. 4. Values of the time constant $T[\mathrm{~ms}]$ for the chamber $V_{k 1}=0.25 \mathrm{~cm}^{3}$

\begin{tabular}{|c|c|c|c|c|c|c|c|c|c|}
\hline $\boldsymbol{d}_{p}[\mathrm{~mm}]$ & \multicolumn{3}{|c|}{$\mathbf{1 . 2 1 1}$} & \multicolumn{3}{|c|}{1.405} & \multicolumn{3}{c|}{$\mathbf{1 . 6 1 0}$} \\
\hline $\boldsymbol{d}_{\boldsymbol{w}}[\mathrm{mm}]$ & $\mathbf{0 . 5 7 0}$ & $\mathbf{0 . 6 2 5}$ & $\mathbf{0 . 7 2 0}$ & $\mathbf{0 . 6 2 5}$ & $\mathbf{0 . 7 2 0}$ & $\mathbf{0 . 8 3 0}$ & $\mathbf{0 . 7 2 0}$ & $\mathbf{0 . 8 3 0}$ & $\mathbf{1 . 0 2 0}$ \\
\hline $\boldsymbol{d}_{\mathbf{n}} \boldsymbol{d}_{\boldsymbol{w}} / \boldsymbol{d}_{\boldsymbol{p}}$ & $\mathbf{0 . 4 7 1}$ & $\mathbf{0 . 5 1 6}$ & $\mathbf{0 . 6 0 3}$ & $\mathbf{0 . 4 4 4}$ & $\mathbf{0 . 5 2 0}$ & $\mathbf{0 . 5 9 1}$ & $\mathbf{0 . 4 4 7}$ & $\mathbf{0 . 5 1 6}$ & $\mathbf{0 . 6 3 3}$ \\
\hline$D_{c}=1.5$ & 12.51 & 8.85 & 7.64 & 9.03 & 5.94 & 5.41 & 8.16 & 5.29 & 4.20 \\
\hline$D_{c}=2$ & 14.95 & 10.06 & 8.81 & 10.21 & 7.62 & 5.78 & 8.01 & 5.53 & 5.37 \\
\hline$D_{c}=3$ & 16.96 & 10.92 & 9.61 & 10.72 & 8.79 & 6.25 & 8.66 & 6.14 & 5.74 \\
\hline
\end{tabular}

Tab. 5. Values of the time constant $T[\mathrm{~ms}]$ for the chamber $V_{k 2}=1.22 \mathrm{~cm}^{3}$

\begin{tabular}{|c|c|c|c|c|c|c|c|c|c|}
\hline$d_{p}[\mathrm{~mm}]$ & \multicolumn{3}{|c|}{1.211} & \multicolumn{3}{|c|}{1.405} & \multicolumn{3}{c|}{$\mathbf{1 . 6 1 0}$} \\
\hline $\boldsymbol{d}_{\boldsymbol{w}}[\mathrm{mm}]$ & $\mathbf{0 . 5 7 0}$ & $\mathbf{0 . 6 2 5}$ & $\mathbf{0 . 7 2 0}$ & $\mathbf{0 . 6 2 5}$ & $\mathbf{0 . 7 2 0}$ & $\mathbf{0 . 8 3 0}$ & $\mathbf{0 . 7 2 0}$ & $\mathbf{0 . 8 3 0}$ & $\mathbf{1 . 0 2 0}$ \\
\hline $\boldsymbol{d}_{\mathbf{n}} \boldsymbol{d}_{\boldsymbol{w}} / \boldsymbol{d}_{p}$ & $\mathbf{0 . 4 7 1}$ & $\mathbf{0 . 5 1 6}$ & $\mathbf{0 . 6 0 3}$ & $\mathbf{0 . 4 4 4}$ & $\mathbf{0 . 5 2 0}$ & $\mathbf{0 . 5 9 1}$ & $\mathbf{0 . 4 4 7}$ & $\mathbf{0 . 5 1 6}$ & $\mathbf{0 . 6 3 3}$ \\
\hline$D_{c}=1.5$ & 13.70 & 13.01 & 11.57 & 12.13 & 10.84 & 10.43 & 12.54 & 7.16 & 6.29 \\
\hline$D_{c}=2$ & 16.82 & 15.48 & 13.14 & 13.45 & 13.14 & 10.21 & 10.42 & 7.69 & 7.45 \\
\hline$D_{c}=3$ & 20.00 & 18.41 & 17.38 & 15.30 & 13.02 & 9.58 & 9.07 & 8.11 & 7.64 \\
\hline
\end{tabular}

Tab. 6. Values of the time constant $T[\mathrm{~ms}]$ for the chamber $V_{k 3}=3.90 \mathrm{~cm}^{3}$

\begin{tabular}{|c|c|c|c|c|c|c|c|c|c|}
\hline$d_{p}[\mathrm{~mm}]$ & \multicolumn{3}{|c|}{1.211} & \multicolumn{3}{|c|}{1.405} & \multicolumn{3}{c|}{1.610} \\
\hline $\boldsymbol{d}_{\boldsymbol{w}}[\mathrm{mm}]$ & $\mathbf{0 . 5 7 0}$ & $\mathbf{0 . 6 2 5}$ & $\mathbf{0 . 7 2 0}$ & $\mathbf{0 . 6 2 5}$ & $\mathbf{0 . 7 2 0}$ & $\mathbf{0 . 8 3 0}$ & $\mathbf{0 . 7 2 0}$ & $\mathbf{0 . 8 3 0}$ & 1.020 \\
\hline $\boldsymbol{d}_{=} \boldsymbol{d}_{\boldsymbol{w}} / \boldsymbol{d}_{p}$ & $\mathbf{0 . 4 7 1}$ & $\mathbf{0 . 5 1 6}$ & $\mathbf{0 . 6 0 3}$ & $\mathbf{0 . 4 4 4}$ & $\mathbf{0 . 5 2 0}$ & $\mathbf{0 . 5 9 1}$ & $\mathbf{0 . 4 4 7}$ & $\mathbf{0 . 5 1 6}$ & $\mathbf{0 . 6 3 3}$ \\
\hline$D_{c}=1.5$ & 34.12 & 28.90 & 23.04 & 25.89 & 18.29 & 16.87 & 21.30 & 12.70 & 10.54 \\
\hline$D_{c}=2$ & 35.35 & 27.83 & 22.07 & 26.82 & 26.02 & 16.82 & 22.55 & 15.25 & 12.82 \\
\hline$D_{c}=3$ & 41.88 & 31.14 & 23.93 & 31.14 & 18.48 & 16.98 & 25.39 & 17.21 & 14.29 \\
\hline
\end{tabular}






Fig. 7. Amplitude-frequency characteristics for the air gages with $d_{p}=1.211 \mathrm{~mm}$ and different measuring chambers (K1 to K3)

For the measuring chambers $\mathrm{K} 1$ and $\mathrm{K} 2$, all the examined combinations revealed the normalized amplitudes to lay between 0.987 and 1 , which meant the dynamic error smaller than $1.5 \%$ for the input frequencies below $1.5 \mathrm{~Hz}$. It proved that those air gages could be applied even for faster measurements than assumed. However, some configurations combined with the measuring chamber $V_{k 3}=3.90 \mathrm{~cm}^{3}$ did not meet this requirement. Considering the fact that the value of the time constant $T$ could differ
$100 \%$ between the initial and final values of the measuring range (Rucki and Jermak, 2012), the measuring chamber $V_{k 3}=3.90 \mathrm{~cm}^{3}$ is not recommended for the discussed measuring task. It provides values of $f_{0.95}$ mostly lower than $3 \mathrm{~Hz}$, which may led to the dynamic error larger than estimated one.

It should be noted that the inlet nozzles apart of the determination of the static sensitivity (multiplication) $K$ and the measuring range have impact on the dynamic characteristics. In any configuration, time constant grows longer for smaller inlet nozzles. On the other hand, the values of the upper frequency bound $f_{0.95}$ are larger for larger inlet nozzles, and they are more sensitive to $d_{w}$ when the measuring chamber volume is smaller and measuring nozzle is larger.

From the perspective of the roundness measurement with the air gages, the dynamic characteristics are better if the upper frequency $f_{0.95}$ is larger (ability to measure faster with the acceptable dynamic error). Thus, among the examined combinations of geometrical parameters of the air gages, the best dynamics revealed those of the smaller measuring chamber volume, smaller outer diameters of the measuring nozzles, and bigger inlet nozzle diameters. It can be seen in the diagram (Fig. 8) showing frequencies $f_{0.95}$ for various inlet and measuring nozzles combined with the measuring chamber of volume $V_{k 1}=0.25 \mathrm{~cm}^{3}$.

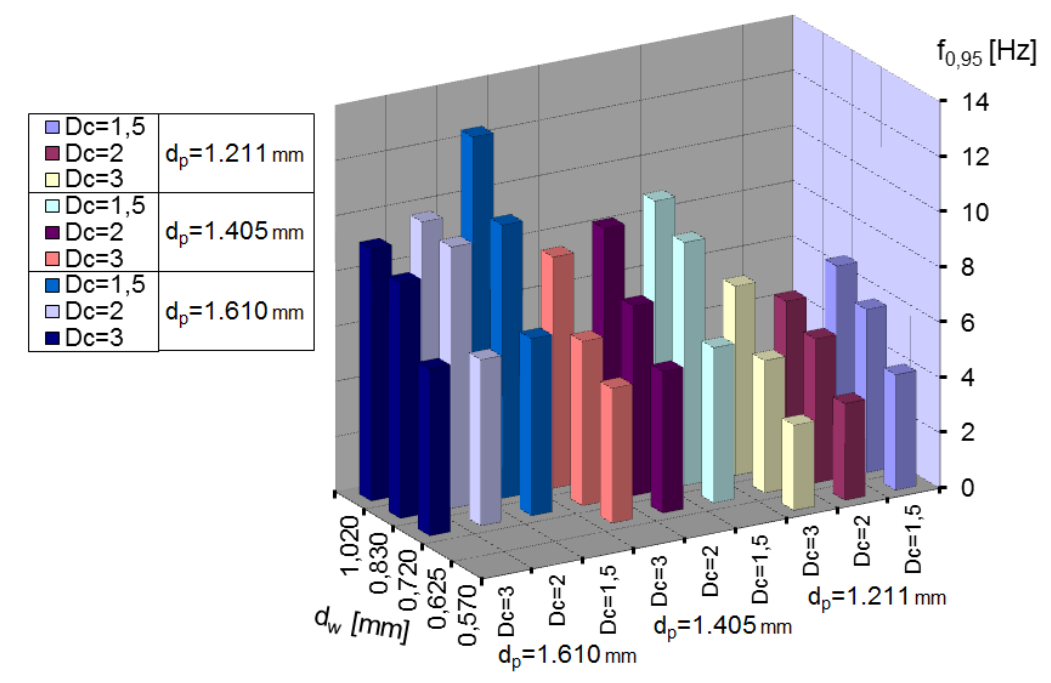

Fig. 8. Upper frequency bound $f_{0.95}$ values for the air gages with the measuring chamber volume $V_{k 1}=0.25 \mathrm{~cm}^{3}$

\section{FINALLY APPROVED AIR GAGES AND METHOD EVALUATION}

The above analysis enabled to evaluate the dynamic characteristics of the air gages of different geometrical parameters proposed to perform the measuring task in the Geoform device with required accuracy. Those configurations that met static requirements on the multiplication and measuring range, underwent dynamic calibration and analysis to eliminate the ones of too large dynamic error. As a result, the following air gages were chosen:

- measuring nozzle $d_{p}=1.610 \mathrm{~mm}$,

- the normalized parameter of outer diameter $D_{c}=3$,

- inlet nozzle $d_{p}=1.020 \mathrm{~mm}$,

- the measuring chamber volume $V_{k} \approx 1.2 \mathrm{~cm}^{3}$.

This configuration had the following static characteristics: mul- tiplication $|K|=0.505 \mathrm{kPa} / \mu \mathrm{m}$ and the measuring range $z_{p}=106$ $\mu \mathrm{m}$. The exact values of the multiplication are shown in the Fig. 9 for each air gage installed in the gage head of the Geoform device.

The proposed out-of-roundness measurement method underwent the overall test through a comparative analysis with the reference data obtained from Talyrond 365 device made by Taylor-Hobson. According to Adamczak et al. (2010), the relative error $\triangle_{M P}$ could be calculated as following:

$\Delta_{M P}=\frac{\Delta R_{m_{i}}-\Delta R_{a_{i}}}{\Delta R_{a_{i}}}$

where: $\Delta \mathrm{R}_{\mathrm{m}_{\mathrm{i}}}$ - out-of-roundness value obtained by the tested method from the i-th point, $\Delta \mathrm{R}_{\mathrm{a}_{\mathrm{i}}}$ - respective value obtained by the reference method. 


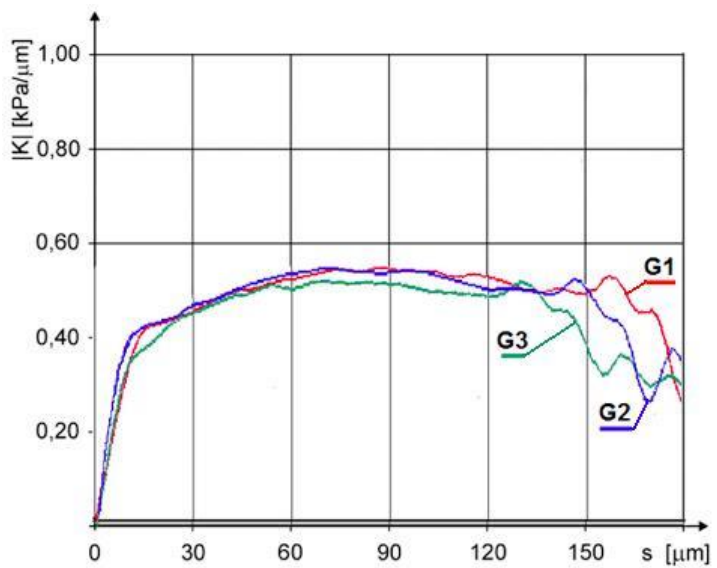

Fig. 9. Experimental graphs of multiplications of the air gages $\mathrm{G} 1, \mathrm{G} 2$ and $\mathrm{G} 3$

After the mean value of all measuring points $\bar{\Delta}_{M P}$ is calculated, the following formula is used for the tested method accuracy MA:

$$
M A=\left|\bar{\Delta}_{M P} \pm u_{p} s\right| \cdot 100 \%,
$$

where: $u_{p}$ - a coefficient of normal distribution for $\mathrm{P}=0.95$, $s$ - standard deviation.

The accuracy of a measuring device to be used for measurement of the geometrical surface structure during the product quality control should lay in the range of $10-25 \%$ (Adamczak et al. 2010). After 100 repetitions with different cylinders, the MA factor for Geoform was calculated as $9.40 \%$, which was highly satisfactory, especially when considering incomparably lower price and faster work of the tested device Geoform.

\section{CONCLUSIONS}

Automated quality control is an important aspect of modern manufacturing process (Milo et al., 2015). The proposed method based on air gages provides quick, relatively cheap and reasonably accurate device for non-contact measurement of inner cylinders with out-of-roundness tolerances of 10-15 $\mu \mathrm{m}$. The air gauges had been found fully capable to measure with the required accuracy, but the problem of dynamic errors was to solve. It was achieved by thorough analysis of the work conditions and dynamic characteristics of the applied air gages, and by the sine input analysis. The configurations of air gages, which appeared to generate too large dynamic errors, were eliminated and replaced by the ones able to work in even faster dynamic conditions than assumed. The methodology of dynamic analysis of the air gages proved to be effective, which resulted in the highly accurate roundness measurement. The Geoform device successfully passed the accuracy test with the reference method.

\section{REFERENCES}

1. Adamczak S., Janecki D., Stępień K. (2010), Qualitative and quantitative evaluation of the accuracy of the V-block method of cylindricity measurements, Precision Engineering, 34, 619-626.

2. Cellary A., Jermak Cz. J. (2009), Pneumatic Method for Reference Out-Of-Roundness Measurement, Proceedings of the 4th International Conference Metrology in Production Engineering, Poznan - Zerkow, 59-64.
3. Derezynski J., Jakubowicz M. (2016), Verification tests of the air gauges metrological characteristics, Mechanik, 3, 196-199.

4. Dmitriev V.N., Chernyshev V.I. (1958), Calculation of the time domain characteristics of the pneumatic flow-through chambers, Avtomatika i telemehanika, 12, 1118-1125 (in Russian).

5. Figliola R.S., Beasley D.E. (2006), Theory and Design for Mechanical Measurements, $4^{\text {th }}$ ed., John Wiley\& Sons Inc., Clemson.

6. Gao R.D., Tang X., Gordon G., Kazmer D.O. (2014), Online product qualty monitoring through in-process measurement, CIRP Annals Manufacturing Technology, 63(1), 493-496.

7. Grandy D., Koshy P., Klocke F. (2009), Pneumatic non-contact roughness assessment of moving surfaces, CIRP Annals Manufacturing Technology, 58(1), 515-518.

8. Jermak Cz. J., Rucki M. (2012), Air Gauging: Static and Dynamic Characteristics, IFSA, Barcelona.

9. Jermak Cz.J., Cellary A., Rucki M. (2010), Novel method of noncontact out-of-roundness measurement with air gauges, Proceedings of the euspen $10^{\text {th }}$ International Conference, Delft, 71-74.

10. Jun Liu et al. (2012), Design and accuracy analysis of pneumatic gauging for form error of spool valve inner hole, Flow Measurement and Instrumentation, 23, 26-32.

11. Menzies I., Koshy P. (2009), In-process detection of surface porosity in machined castings, International Journal of Machine Tools \& Manufacture, 49(6), 530-535.

12. Milo M.W., Roan M., Harris B. (2015), A new statistical approach to automated quality control in manufacturing processes, Journal of Manufacturing Systems, 36, 159-167.

13. O'Neill P., Sohal A., Teng Ch.W. (2016), Quality management approaches and their impact on firms' financial performance - An Australian study, International Journal of Production Economics, 171, 381-393.

14. Pollard J.H. (1977), A Handbook of Numerical and Statistical Techniques, Cambridge University Press, Cambridge.

15. Rucki M. (2011), Dynamic properties of the back-pressure air gauges with small measuring chambers, Poznan University of Technology, Poznan (in Polish).

16. Rucki M., Barisic B. (2009), Response Time of Air Gauges With Different Volumes of the Measuring Chambers, Metrology and Measurement Systems, 16(2), 289-298.

17. Rucki M., Jermak Cz. J. (2012), Dynamic Properties of Small Chamber Air Gages, Journal of Dynamic Systems, Measurement, and Control, 134(1), p. 011001 (6 pages).

18. Shiraishi M., Yamagiwa T., Ito A. (2002), Practical dimensional error control and surface roughness inspection in turning, Proceedings of ASME-2002 Mechanical Engineering Congress and Exposition, New Orleans, 45-51.

19. Stępień K. (2010), In situ measurement of cylindricity - Problems and solutions, Precision Engineering, 38, 697-701.

20. Tsidulko F.V. (1965), Dynamics of the pneumatic devices for the dimensional measurement, Mashinostroyeniye, Moskva (in Russian).

21. Vacharanukul K., Mekid S. (2005), In-Process Dimensional Inspection Sensors, Measurement, 38, 204-218.

22. Valicek J. et al. (2007), An investigation of surfaces generated by abrasive waterjets using optical detection, Journal of Mechanical Engineering, 53(4), 224-232.

23. Wang Y. H. et al. (2005), An Automatic Sorting System Based on Pneumatic Measurement, Key Engineering Materials, 295-296, 563-568.

24. Wieczorkowski S. (1995), Automatic regulation of the rotational speed of the pneumatic misroturbines, Research Publication Series of Lodz University of Technology, No. 703, Lodz (in Polish).

25. Yribarren R. (1955), The pneumatic method applied to dynamic measurement, Proceedings of the Symposium on Engineering dimensional metrology, London, 225-240.

This work was supported by the Ministry of Science and Higher Education, Poland, project N505 010 32/1555. 